\title{
Flore bactérienne du lait cru de la région de Téhéran
}

\author{
par \\ G. KARIM et Gh. KACHANI \\ Département de l'Hygiène Alimentaire \\ Université de Téhéran, B.P. 3262, Téhéran (Iran) \\ Directeur : A. FARKHONDEH
}

\section{INTRODUCTION}

En 1935, Wilson et al. [9] ont étudié la flore bactérienne et le temps de réduction du bleu de méthylène du lait cru. En 1952, Rowlands et Garvie [4] ont étudié la distribution de différentes bactéries sur douze échantillons de lait cru conservés pendant $24 \mathrm{~h}$ à $14^{\circ} \mathrm{C}$. En 1957, Abd-el Malek et Gibson [1] ont fait une étude comparative de la flore bactérienne sur les échantillons de lait frais des vaches traites aseptiquement et ceux, collectés après la traite, ayant une flore microbienne élevée. Au cours des années 1962, 1973, 1974 et 1976, Thomas et al. [5, 6, 7, 8] ont fait une étude très étendue sur la flore microbienne du lait cru dans le système de ramassage par camion-citerne, bactéries psychrotrophes des laits crus réfrigérés et la flore microbienne des laits pasteurisés réfrigérés. En 1974, au moment où l'on installait la première usine de traitement de lait U.H.T. en Iran, Farkhondeh (1974) a fait une étude sur la flore sporulée du lait cru de grand mélange de la région de Téhéran.

Tenant compte de l'importance de la flore microbienne de lait cru sur les différents procédés de traitement thermique et d'assainissement, nous avons pensé utile de faire une étude en vue de mieux connaître la flore microbienne de lait cru de la région de Téhéran.

\section{MATERIELS ET METHODES}

Nous avons prélevé au total soixante-douze échantillons de lait cru des bidons délivrés à la Centrale laitière de Téhéran.

Le prélèvement était effectué d'une façon stérile et les échantillons étaient transportés dans les conditions frigorifiques au labo- 
ratoire et examinés. Sur chaque échantillon, nous avons fait une numération totale selon la norme internationale FIL/IDF 3 : 1958. A partir de chaque boîte contenant entre 30 et 300 colonies, nous avons isolé au hasard 10 colonies, ensemencé dans les tubes de gélose nutritive et mis à l'étuve de $30^{\circ} \mathrm{C}$ pendant $24 \mathrm{~h}$. A partir de ces tubes, devenus opaques, nous avons porté par anse platine sur une boîte contenant la gélose nutritive plus 10 p. 100 de lait écrémé et après $24-48 \mathrm{~h}$ d'incubation à $30^{\circ} \mathrm{C}$, nous avons isolé une colonie bien distincte et coloré par la méthode Gram. Après 48-72 h d'incubation de la culture purifiée, les bâtonnets Gram + sont colorés avec du méthyle violet pour la différenciation des spores. L'épreuve à la catalase sur lame est effectuée en mélangeant un peu de la culture de la boîte avec une goutte d'eau oxygénée à 10 volumes. Les bâtonnets Gram - sont ensemencés sur le bouillon Mc Conkey et après $72 \mathrm{~h}$ d'incubation à $30^{\circ} \mathrm{C}$ la production de l'acide et du gaz est vérifiée.

D'après les résultats obtenus et en utilisant la forme suivante, nous avons identifié les bactéries :

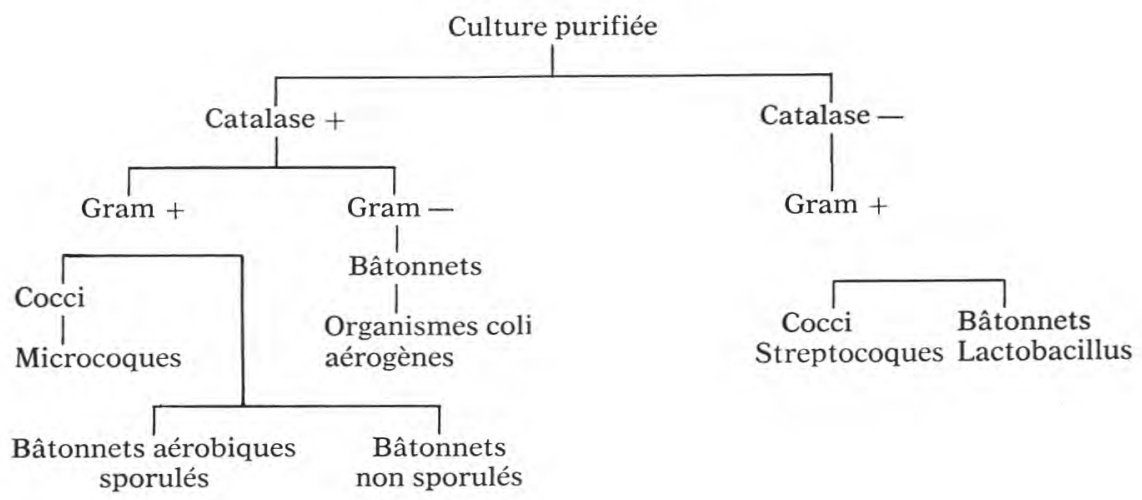

\section{RESULTATS ET DISCUSSION}

Le tableau 1 montre les résultats de la numération totale. Sur soixante-douze échantillons examinés, trois échantillons, soit 4,1 p. 100 avaient une numération totale de l'ordre de $1 / 5 \times 10^{5}-5 \times 10^{5}$. 95,7 p. 100 des échantillons de lait cru examinés avaient une numération totale de $>5 \times 10^{5}$. 


\section{TABLEAU 1}

Résultats de la numération totale

\begin{tabular}{|c|c|c|c|c|}
\hline $\mathrm{NT} / \mathrm{ml}$ & Nombre & p. 100 & Nombre & p. 100 \\
\hline $1,5 \times 10^{5}-5 \times 10^{5}$ & 3 & 4,1 p. 100 & 22 & 3,7 p. 100 \\
\hline$>5 \times 10^{5}-2 \times 10^{6}$ & 4 & 5,5 p. 100 & 30 & 5,1 p. 100 \\
\hline$>2 \times 10^{B}-5 \times 10^{6}$ & 17 & 23,6 p. 100 & 131 & 22,3 p. 100 \\
\hline$>5 \times 10^{6}-3 \times 10^{7}$ & 31 & 43 p. 100 & 263 & 44,8 p. 100 \\
\hline$>3 \times 10^{7}$ & 17 & 23,6 p. 100 & 140 & 23,9 p. 100 \\
\hline Total & 72 & & 586 & \\
\hline
\end{tabular}

Sur soixante-douze échantillons de lait nous avons fait au total cinq-cent-quatre-vingt-six ensemencements. Le tableau 2 montre la distribution des différentes bactéries.

Comme le montre le tableau 2, les trois échantillons de lait qui étaient produits dans les conditions hygiéniques relativement satisfaisantes $\left(\mathrm{NT}=1,5 \times 10^{5}-5 \times 10^{5}\right)$ avaient une flore microbienne dont 54,5 p. 100 des micro-organismes dominants sur vingt-deux cultures étaient constitués par les microcoques. Les microcoques étaient également la flore dominante dans les trente cultures de lait cru avec une NT de $>5 \times 10^{5}-2 \times 10^{6}$ (33,3 p. 100) mais venaient ensuite les bâtonnets Gram - (20 p. 100) et les coliformes (16,6 p. 100). Sur cent-trente et une cultures avec une NT de $2 \times 10^{6}-5 \times 10^{6}$ la flore dominante était les coliformes $(20,6$ p.100) et ensuite les bactéries Gram + sporulées et non sporulées $(19,8$ p. 100). Sur les deux-centsoixante-trois cultures avec une NT de $>5 \times 10^{6}-3 \times 10^{7}$ la flore dominante était les bactéries Gram + sporulées (19 p.100), bâtonnets Gram - (19 p. 100) et coliformes (18,2 p. 100). Dans les centquarante cultures avec une NT de $>3 \times 10^{7}$ la flore dominante était les bactéries Gram + sporulées (25,7 p. 100,), coliformes (22,1 p. 100) et microcoques $(18,5$ p. 100). D'une façon générale et sans se rendre compte de la numération totale, sur cinq-cent-quatre-vingt-six cultures effectuées la flore dominante était les bactéries Gram + sporulées $(19,6$ p. 100), coliformes (19,6 p. 100) et microcoques (18,6 p. 100). 
TABLEAU 2. - Distribution des différentes bactéries

\begin{tabular}{|c|c|c|c|c|c|c|c|c|c|c|c|c|}
\hline \multirow{2}{*}{ Micro-organismes } & \multicolumn{2}{|c|}{$1,5 \times 10^{5}-5 \times 10^{5}$} & \multicolumn{2}{|c|}{$>5 \times 10^{5}-2 \times 10^{6}$} & \multicolumn{2}{|c|}{$>2 \times 10^{6}-5 \times 10^{6}$} & \multicolumn{2}{|c|}{$>5 \times 10^{6}-3 \times 10^{7}$} & \multicolumn{2}{|c|}{$>3 \times 10^{7}$} & \multicolumn{2}{|c|}{$\begin{array}{c}\text { Total } \\
\text { des cultures }\end{array}$} \\
\hline & Nombre & p. 100 & Nombre & p. 100 & Nombre & p. 100 & Nombre & p. 100 & Nombre & p. 100 & Nombre & p. 100 \\
\hline Bactéries Gram + non sporulées & 6 & 27,2 & 1 & 3,4 & 26 & 19,8 & 36 & 13,6 & 18 & 12,8 & 87 & 14,8 \\
\hline Bactéries Gram + sporulées & - & - & 3 & 10,3 & 26 & 19,8 & 50 & 19 & 36 & 25,7 & 115 & 19,6 \\
\hline Bactéries Gram - & - & - & 6 & 20,6 & 20 & 15,2 & 50 & 19 & 15 & 1,7 & 91 & 15,5 \\
\hline Coliformes & 4 & 18,1 & 5 & 17,6 & 27 & 20,6 & 48 & 18,2 & 31 & 22,1 & 115 & 19,6 \\
\hline Lactobacilles & - & - & 2 & 6,8 & 7 & 5,3 & 21 & 7,9 & 6 & 4,2 & 36 & 6,1 \\
\hline Streptocoques & - & - & 2 & 6,8 & 6 & 4,5 & 17 & 6,4 & 8 & 5,7 & 33 & 5,6 \\
\hline Microcoques & 12 & 54,5 & 10 & 34,4 & 19 & 14,5 & 42 & 15,9 & 26 & 18,5 & 109 & 18,6 \\
\hline Total & 22 & & 30 & & 131 & & 263 & & 140 & & 586 & \\
\hline
\end{tabular}




\section{CONCLUSION}

Les résultats obtenus dans cette étude montrent la nécessité absolue de l'application des méthodes et des mesures d'hygiène au niveau de la production du lait et de son transport de la ferme à l'usine. A l'heure actuelle, la température de la pasteurisation est de quelques degrés plus élevée que la norme, mais si ces mesures hygiéniques sont appliquées au niveau de la production, on pourrait obtenir un lait pasteurisé de meilleure qualité et d'une conservabilité plus longue.

\section{Ré s u mé}

Soixante-douze échantillons de lait cru de mélange étaient examinés pour la détermination de la flore dominante. La flore microbienne des échantillons qui ont été produits dans les conditions hygiéniques satisfaisantes était dominée par les microcoques. La flore microbienne des échantillons ayant une numération des coliformes de l'ordre de $>2 \times 10^{5}-5 \times 10^{6}$ était dominée par les coliaérogènes, les bactéries sporulées Gram + et les bâtonnets non sporulés. La flore des échantillons ayant une numération totale élevée était dominée par les bactéries Gram + sporulées, les bactéries Gram - et les coli-aérogènes.

\section{S u m m a r y}

THE MICROFLORA OF RAW MILK IN TEHRAN AREA

A total of seventy-two samples of raw mixed milk was examined for determination of the dominant organisms of the microflora. The microflora of samples with satisfactory hygienic condition was dominanted by Micrococci. The microflora of samples with colony count range from $>2 \times 10^{5}-5 \times 10^{6}$ was dominated by coli-aerogenese organisms, G+ve sporeformers and non sporeformers rods. The series of samples with high colony counts showed a dominant microflora with $\mathrm{G}+\mathrm{ve}$ sporeforming rods, $\mathrm{G}-\mathrm{ve}$ rods and coli-aerogenese organisms respectively. 


\section{Bibliographie}

[1] Abd-el Malek (Y.) and Gibson (T.) (1957). - The development of bacterial populations in milk. Canad. J. Microbiol., 3, 203.

[2] Carreira (D. F. C.), Clegg (L. F.), Clough (P. A.) and Thiel (C. C.) (1955). The effect of steam, hypochlorite and custic soda used for treating direct-tocan milking equipment on the bacteriological quality and flora of milk. $J$. Dairy Res., 22, 166.

[3] FARKHONDEH (A.) (1974). - Aerobic sporeforming microorganisms in the mixed of Tehran area. XIX International Dairy congress India. Vol. $1 \mathrm{E}$.

[4] GaRvie (E. I.) and Rowlands (A.) (1952). - The role of microorganisms in dye reduction and keeping quality tests. J. Dairy Res., 19, 133.

[5] Thomas (S. B.), Hobson (P. M.), Bird (E. R.), King (K. P.), Druce (R. G.) and Cox (D. R.) (1962). - The microflora of Raw milk as determined by plating on Yeastrel. Milk Agar incubated at 30 ${ }^{\circ}$ C. J. Appl. Bact., 25 (1), 107-115.

[6] Thomas (S. B.) (1973). - Psychrotrophic bacteria in refrigerated bulk collected raw milk. Dairy Industries, 38 (1).

[7] Thomas (S. B.) (1974). - Microflora of bulk collected Milk. Dairy Industries, 39 (7).

[8] Thомas (S. B.) (1976). - The bacterial content of bulk farm milk tank. A review. Dairy Industries, 41 (5).

[9] Wilson (G. S.), Twigg (R. S.), Wright, (R. C.), Hendry (C. B.), Cowell, (M. P.) and MAIER (I.) (1935). - The bacteriology grading of milk Spec. Rep. Ser. Med. Res. Coun. No: 206 London : H.M.S.O. 